\title{
Intraosseus Tophaceous Gout of the Patella. A Case Report and Review of the Literature
}

\author{
Joan Pijoan ${ }^{1,3 *}$, Joan Minguell ${ }^{1,3}$, M Mercedes Reverté ${ }^{1,3}$, Nikaoly Ciriaco ${ }^{2,3}$ and Enric Castellet ${ }^{1,3}$ \\ ${ }^{1}$ Department of Traumatology and Orthopaedics, University Hospital of Vall d'Hebrón, Spain \\ ${ }^{2}$ Department of Pathology, University Hospital of Vall d'Hebrón, Barcelona, Spain \\ ${ }^{3}$ Universitat Autònoma de Barcelona, Barcelona, Spain
}

*Corresponding author: Joan Pijoan, Department of Traumatology and Orthopaedics, University Hospital of Vall d'Hebrón, Spain

\section{ARTICLE INFO}

Received: 幽 January 18, 2021

Published: 幽 January 26, 2021

Citation: Joan Pijoan, Joan Minguell, M Mercedes Reverté, Nikaoly Ciriaco, Enric Castellet. Intraosseus Tophaceous Gout of the Patella. A Case Report and Review of the Literature. Biomed J Sci \& Tech Res 33(3)-2021. BJSTR. MS.ID.005395.

\begin{abstract}
Patellar bone tumors are rare entities. The differential diagnosis is extensive, including both benign and malignant tumors. Intraosseous gout tophi should be considered. The clinical and imaging features of this entity are unspecific, although in some cases it may carry a high suspicion diagnostic. We present a case of patella gout tophi who's clinical and imaging tests raised diagnostic questions, so an excisional biopsy was performed for diagnosis and treatment.
\end{abstract}

\section{Introduction}

Patellar tumors are rare entities, representing only $0.12 \%$ of all bone tumors in the United States. The $70 \%$ of all patella tumors are benign, with giant cell tumor and chondroblastoma being the most common, and the remaining 30\% are malignant tumors, including the most common malignant primary tumor, osteosarcoma. Metastases are rare in the patella; there is a review of cases published between 1960 and 2016 that found only 44 reported cases. Benign tumors include giant cell tumor $33 \%$ of all patella tumors), chondroblastoma (16\%), enchondroma (5\%), aneurysmal bone cyst (4\%), bone cyst (4\%), osteoid osteoma (3\%), osteoblastoma (2\%), and osteochondroma (2\%) [1,2]. Intraosseous crystal deposits account for $<1 \%$ of patellar bone tumors. Gouty arthropathy or gout is an entity caused by the deposit of monosodium urate crystals within joints and tendons. Intraosseous involvement of the patella is a rare condition. Gout affecting the superolateral region of a patella bipartita is described in the literature, also affecting the adjacent tendon structures. We present a case of patellar tumor due to monosodium urate crystals whose differential diagnosis was vast because the low specificity of the initial radiological images. It should be noted that intraosseous gout does not present specific clinical or radiological features. For the same reason, an adequate study of the lesion is required in order to obtain an indicative diagnosis before the biopsy is performed [3].

\section{Clinical Case}

We present the case of a 67-year-old male patient with a history of hypertension, dyslipidemia and hyperuricemia, treated with allopurinol for 15 years. Although this treatment, he presented occasional gout pain crises in hallux. Initial symptoms appeared with anterior inflammatory knee pain. During physical examination it did not present anomalies in the visual inspection, emphasizing selective pain on the palpation of the middle third of patella and without range of motion limitation. We performed a MRI, it reported grade II patellar chondromalacia and minimal patellar bursitis [4-6]. After 2 weeks of treatment with rest, cryotherapy and non-steroidal anti-inflammatory drugs, the pain subsides. The patient remained completely asymptomatic until, five months after the previous crisis, the pain recurred with greater intensity as referred by the patient. The physical examination this time is more striking, as it shows clear pre-patellar inflammatory signs and an 
evading flexion because of pain. The symptoms lasts more than two weeks despite conservative treatment, which is why we decided to perform a simple knee x-ray and a new MRI. The simple x-ray of the knee showed a patellar lesion with a lytic appearance (Figure 1). The MRI showed a hyperintense T2 lesion with an intermediate signal in the T1 images. The patellar tendon, extremely abnormal in its most proximal portion, showed heterogeneous characteristics with distorted areas in its fibers and with altered signal in all sequences (Figure 2).
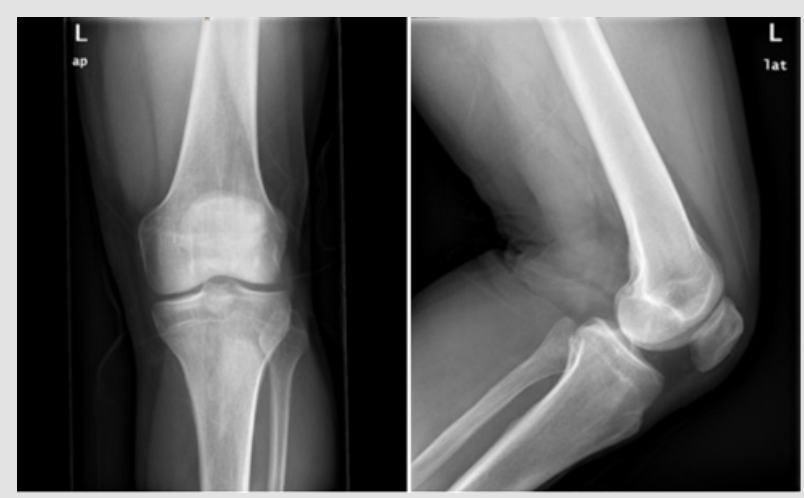

Figure 1: Antero-posterior and lateral view X-rays of the left knee. In the lateral view, a lithic image can be seen in the most anterior area of the patella. It has well-defined margins and no other associated lesions.
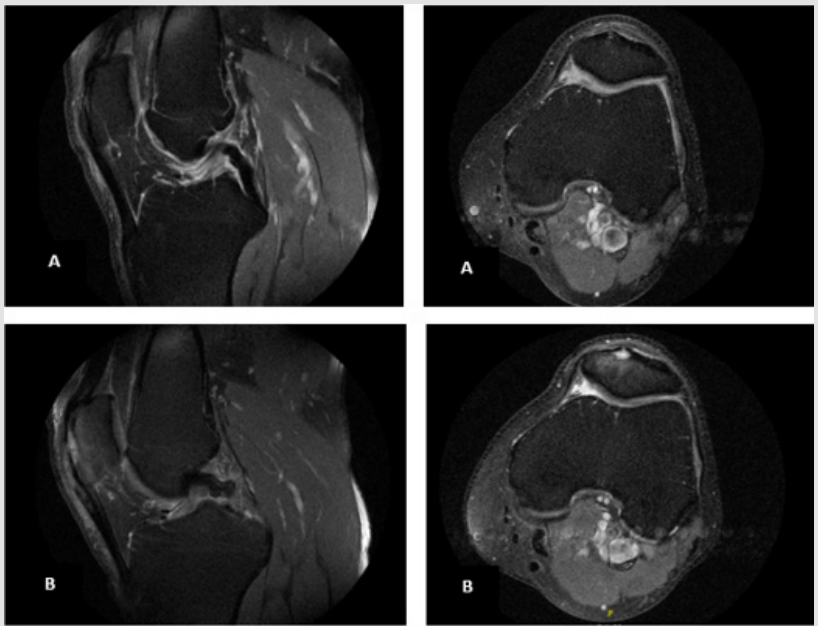

Figure 2: MRI of the left knee.

a) Initial MRI, small hyperintense lesion can be seen in T2. Initially this image was oriented by expert radiologists, as a bone lesion associated with a tendinopathy.

b) MRI 5 months after the initial MRI. Here we see a more evident lesion, T2 hyperintense, with well-defined margins but there seems to be a break in the cortical plus anterior of the patella.

Given the findings found in the MRI, it was decided to perform a knee CT to define the lesion. This shows a patellar tendinopathy with the presence of calcic deposits, thickening of the pre-patellar soft tissues and presence of a lytic bone lesion in the anterior aspect of the patella. The bone lesion was $8 \mathrm{mmx} 3 \mathrm{~mm} \times 3 \mathrm{~mm}$ (Figure 3 ).
Because the possibility of metastasis, we performed a simple thorax x-ray and a gammagraphy as an extension study, no distant lesions were described. Based on this lesion, a wide differential diagnosis was proposed. The main suspected diagnosis was an intraosseous hemangioma [6-10]. In addition, as differential diagnosis, osteoblastoma, giant cell tumor, simple bone cyst, chondroblastoma and osteoid osteoma were included. The MRI image, according to radiologists, was an active lesion but without aggressive features. After discussing the case in a multidisciplinary committee, and upon suspicion of a hemangioma, an excisional biopsy of the lesion was recommended. We decided not to perform a CT-guided biopsy because, given its size and its superficial location, a block excisional biopsy with a safety margin was possible. For this purpose, an anterior approach was performed on the midline of the knee; intraoperatively, a whitish exudate was found in the anterior area of the patella and in the insertion area of the patellar tendon (Figure 4). A block resection of the lesion and part of the surrounding bone was performed. A bone fragment measuring $3.3 \times 1.1 \times 1.4 \mathrm{~cm}$ was obtained.

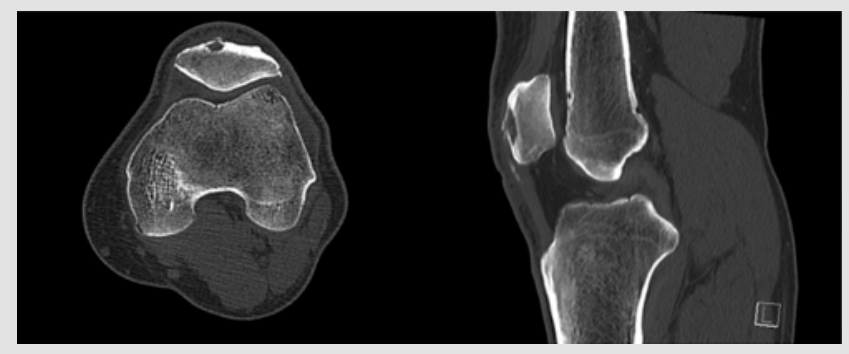

Figure 3: A knee CT scan is performed to assess the size of the injury so that good preoperative planning can be done. We found a lesion measuring $8 \mathrm{~mm} \times 3 \mathrm{~mm} \times 3 \mathrm{~mm}$. It is important to emphasize that the tumor is in the most superficial part of the middle third of the patella, which led us to perform a block resection of the entire tumor.

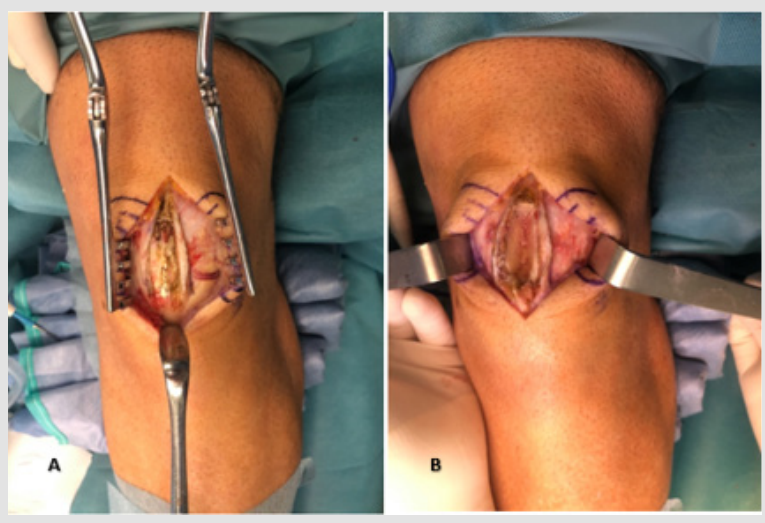

Figure 4: Intraoperative pictures. We observed an anterior knee approach.

a) We can notice, unlike those observed in the MRI, cortical indemnity. We can also see clusters of a dense, whitish-looking substance.

b) Image in which we can see the appearance of the patella after resection of the bone block. 
The histological study of the sample showed an inflammatory fibrous lesion with several non-necrotizing granulomas, and around these it presented fragments of eosinophilic, pale and amorphous material, surrounded by multinucleated giant cells, compatible with deposits of monosodium urate microcrystals. Within the lesion, trabeculae of newformed reticular bone were evident. No areas of atypia or necrosis were found (Figure 5). In the postoperative period, knee flexion was limited for 2 weeks to promote wound healing, and then a gradual flexion of the knee was initiated. After six months post-surgery, the patient had a full range of motion ( 0 to 130 degrees) without wandering or discomfort. During this 6-month period there were no clinical or radiological signs of local recurrence [11-15].
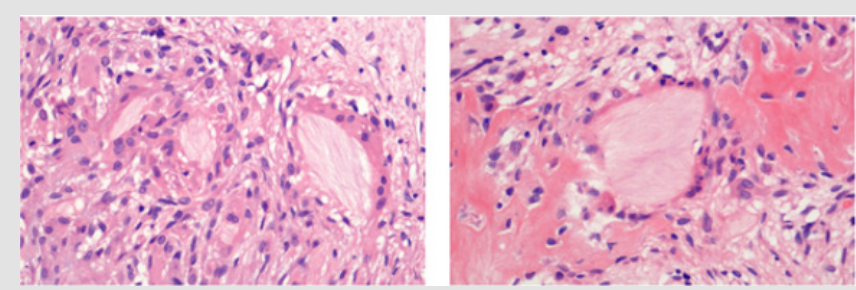

Figure 5: Foreign body giant cell reaction surrounding pink proteinaceous material (dissolved crystals, due to inadequate preservation of them).

\section{Discussion}

Gout is an inflammatory arthropathy characterized by monosodium urate deposits in the joints. This is favored by increased plasma uric acid concentration. Hyperuricemia is defined as uric acid values above $6.8 \mathrm{mg} / \mathrm{dL}$, which is the concentration at which uric acid precipitates under physiological conditions of $\mathrm{pH}$ and body temperature. Among the causes of hyperuricemia there are genetic alterations in purine metabolism, chronic renal failure and a purine rich diet. The gout tophi are a conglomerate of inflammatory cells and monosodium urate crystals. The actual incidence of intraosseous gout in patella is not known due to its rarity. The first case reported in the literature was described by Peloquin and Graham in 1955, in this case the authors made the diagnosis without biopsy and treated the lesion conservatively, by intensifying therapy to reduce uric acid, obtaining remission of pain. In addition to this case, there are other published case reports (Table 1), although they are scarce. Some of the authors who published these case reports suggest that the formation of gouty tophi may be associated with previous inflammatory processes, the presence of bipartite patella or a history of previous trauma $[16,17]$. It has been described that the monosodium urate precipitation is favored by a decrease in temperature, which is why it is common to see it in the interphalangeal joints of the fingers.

Table 1: Cases published in the literature of intra-osseous gout tophi in patella. There are also published cases of fractures associated with erosions by gout tophi, these cases are not shown in the table.

\begin{tabular}{|c|c|c|c|c|c|}
\hline Authors & Year & Age, sex & History of gout & Diagnosis & Treatment \\
\hline Peloquin LU [6] & 1955 & $43, \mathrm{M}$ & Yes & Clinical + radiological findings & Conservative \\
\hline Lyford J $3^{\text {rd }}[9]$ & 1956 & $34, \mathrm{M}$ & No & Histology & Surgical \\
\hline Cohn BT [10] & 1988 & 52. M & Yes & Histology & Surgical \\
\hline \multirow{7}{*}{ Recht MP [11] } & \multirow{7}{*}{1994} & $38, \mathrm{M}$ & Yes & Histology & $\begin{array}{c}\text { Bilateral: } \\
\text { - Right: Surgical - Left: } \\
\text { Conservative }\end{array}$ \\
\hline & & $40, \mathrm{M}$ & No & Histology & Surgical \\
\hline & & $71, \mathrm{M}$ & Yes & $\begin{array}{c}\text { Plain radiography + } \\
\text { arthrocentesis }\end{array}$ & Conservative \\
\hline & & $23, \mathrm{M}$ & No & Histology & Surgical \\
\hline & & $52, \mathrm{~F}$ & Yes & $\begin{array}{l}\text { Plain radiography + } \\
\text { arthrocentesis }\end{array}$ & Conservative \\
\hline & & 23. M & No & Histology & Surgical \\
\hline & & 66. M & No & Histology & Surgical \\
\hline \multirow[t]{3}{*}{ Reber P [12] } & 1996 & $29, \mathrm{M}$ & No & Histology & Surgical \\
\hline & & 28. M & No & Histology & Surgical \\
\hline & & $76, \mathrm{M}$ & No & Histology & Surgical \\
\hline Sato J [13] & 2001 & $53, \mathrm{M}$ & No & Histology & Surgical \\
\hline Kobayashi K [14] & 2005 & $34, \mathrm{M}$ & Yes & Histology & Surgical \\
\hline \multirow{2}{*}{ Hopper G [15] } & \multirow{2}{*}{2012} & $70, \mathrm{M}$ & No & Histology & Conservative \\
\hline & & $34, \mathrm{M}$ & No & Histology & Conservative \\
\hline Clark S [16] & 2016 & 52. M & Yes & MRI & Conservative \\
\hline
\end{tabular}




\begin{tabular}{|c|c|c|c|c|}
\hline \multirow{2}{*}{ Kester C [17] } & \multirow{2}{*}{2018} & $59, \mathrm{M}$ & Yes & Histology \\
\cline { 3 - 5 } & & $57, \mathrm{M}$ & Yes & Histology \\
\cline { 3 - 5 } & & $69 . \mathrm{M}$ & Yes & CT \\
\hline Chiu M & 2020 & $48 . \mathrm{M}$ & No & Histology \\
\hline
\end{tabular}

The clinic is not specific and occasionally vague, so there is sometimes a clinical-radiological discrepancy. In chronic gout, tophi can be palpated as dense masses adjacent to the joints. Complementary tests such as simple radiology, MRI or CT show aggressive lesions, so this is usually a cause for concern. A complete anamnesis investigating a history of gout may be helpful in such cases, but without an arthrocentesis or biopsy the diagnosis is not definitive. In addition, it is rare for the initial clinical presentation to be a bone mass without further associated symptoms. The first thing that should be done when suspecting intraosseous gout is an assessment of the uric acid levels in plasma, however, the presence of hyperuricemia is inconsistent, may be absent in acute episodes or in asymptomatic patients. The most specific features of plain radiography are the presence of juxtaarticular and intra-articular erosions with sclerotic margins and protruding edges. In some patients, plain radiography shows no alterations, so it is recommended to perform a Magnetic Resonance Imaging (MRI), which usually shows small bone erosions, synovial pannus, bone edema and edema of adjacent soft tissues. Tophi are characteristically shown as hypo or isointense lesions in T1, the T2 intensity is variable depending on the amount of calcium in the tophi. Tophi in the knee are usually found intra-articular, especially in Hoffa fat, lateral edge of lateral femoral condyle and intercondylar fossa [13]. Sometimes we can find perilesional calcifications, like over the patellar tendon, in these cases it can indicate a microcrystals deposit disease, such as gout.

Most cases of gouty arthropathy are treated conservatively, however, large masses may cause limitation of joint balance and soft tissue stress. Gouty arthropathy presents cumulative effects, so that large erosions and advanced tendon degenerations may end in pathological fractures and in tendon rupture, respectively. We believe that surgical treatment should be reserved for three occasions. First when the clinic does not cease after prolonged conservative treatment. Secondly, when the erosion or tophi may evolve into a major complication. And finally, when the diagnosis is doubtful, a biopsy or arthrocentesis should be performed to have histological confirmation. It should be noted that monosodium urate crystals are soluble in water and therefore dissolve in formalin. Therefore, if there is a high index of suspicion of gouty tophi, alcohol fixation may better preserve the crystalline architecture of the tophi; however, most biopsies of bone lesions are fixed in formalin, which sometimes makes it impossible to identify the crystals. Most of the authors presented in Table 1 refer that the surgical treatment they performed consisted of a curettage of the lesion. In our case, we preferred to perform a block resection of the lesion, because we did not perform a previous biopsy and since we did not know the diagnosis, we tried to keep the margins free of the lesion. Despite this, having a previous diagnosis by puncture-biopsy, curettage seems to us a good therapeutic option.

\section{Conclusion}

our case concerns a patient affected by a painful patellar lytic tumor in a male with good control of uric acid levels. In view of the initial image and the suspicion of other tumor lesions, it was decided to carry out an extension study and an open biopsy by resecting the whole tumor. This case shows that the gout tophi should be considered when making a differential diagnosis of a patellar tumor, although some cases are occasionally diagnosed without a biopsy, it is prudent to seek histological confirmation when the clinical or imaging results are indeterminate.

\section{References}

1. Devaney k (1996) Unni KK: Osteosarcoma. Dahlin's bone tumors. General aspects and data on 11.087 cases. In Devaney k (Eds.), $5^{\text {th }}(\mathrm{edn}$.). Lippincot Raven Publishers, Philadelphia, pp. 143-184.

2. Mercuri M, Casadei R (2014) Patellar tumors. Clin Orthop Relat Res. 389: 35-46.

3. Chowalloor PV, Siew TK, Keen HI (2014) Imaging in gout: a review of the recent developments. Ther Adv Musculoskelet Dis 6(4): 131-143.

4. Doherty M (2009) New insights into the epidemiology of gout. Rheumatology 48(suppl 2): ii2-ii8.

5. Peluquin LU, Graham JH (1955) Gout of the patella; report of a case. N Engl J Med 253(22): 979-980.

6. Schlesinger N, Baker DG, Schumacher HR Jr (1997) Serum urate during bouts of acute gouty arthritis. J Rheumatol 24(11): 2265-2266.

7. Ko KH, Hsu YC, Lee HS (2010) Tophaceous gout of the knee. J Clin Rheumatol 16(5): 209-214.

8. Lyford J, Shapiro D (1956) Gout as a cause of isolated circumscribed cyst of the patella; report of a case. Radiology 66(3): 380-382.

9. Cohn BT, Ibarra JA, Jackson DW (1988) Erosion of the patella secondary to gout. A case report. Am J Sports Med 16(4): 421-423.

10. Recht MP, Seragini F, Kramer J, Dalinka MK, Hurtgen K (1994) Isolated or dominant lesions of the patella in gout: a report of seven patients. Skeletal Radiol 23(2): 113-116.

11. Reber P, Crevoisier X, Noesberger B (1996) Unusual localisation of tophaceous gout. A report of four cases and review of the literature. Arch Orthop Trauma Surg 115(5): 297-299.

12. Sato J, Watanabe H, Shinozaki T, Fukuda T, Shirakura K (2001) Gouty tophus of the patella evaluated by PET imaging. J Orthop Sci 6(6): 604607.

13. Kobayashi K, Deie M, Okuhara A, Adachi N, Yasumoto M (2005) Tophaceous gout in the bipartite patella with intra-osseous and intraarticular lesions: a case report. J Orthop Surg (Hong Kong) 13(2): 199202. 
14. Hopper G, Gupta S, Bethapudi S, Ritchie D, Macduff E (2012) Tophaceous gout of the patella: a report of two cases. Case Rep Rheumatol 2012 253693.

15. Clark S, Evans JM, Armstrong N, Schnitz W (2016) Tophaceous gout with rare involvement of the patella. Radiol Case Rep 11(4):380-385.

ISSN: 2574-1241

DOI: $10.26717 /$ BJSTR.2021.33.005395

Joan Pijoan. Biomed J Sci \& Tech Res

(C) (i) This work is licensed under Creative BY Commons Attribution 4.0 License

Submission Link: https://biomedres.us/submit-manuscript.php
16. Kester C, Wallace MT, Jelinek J, Aboulafia A (2018) Gouty involvement of the patella and extensor mechanism of the knee mimicking aggressive neoplasm. A case series. Skeletal Radiol 47(6): 865-869.

17. Chiu MK, Lewis NA (2020) Intraosseous gout mimicking giant cell tumor of the patella. Skeletal Radiol 49(8):1325-1328.

$\begin{array}{ll}\text { BIOMEDICAL } & \text { Assets of Publishing with us } \\ \text { RESEARCHES } & \text { - Global archiving of articles } \\ \text { - Immediate, unrestricted online access } & \text { - Rigorous Peer Review Process } \\ & \text { - Authors Retain Copyrights }\end{array}$

